\title{
Tracing all patients who received insured dialysis treatment in Japan and the present situation of their number of deaths
}

\author{
Shinichiro Kubo ${ }^{1}$ 'Tatsuya Noda ${ }^{1}$ (1) Tomoya Myojin $^{1}$ - Yuichi Nishioka ${ }^{1}$ - Saho Kanno ${ }^{1} \cdot$ Tsuneyuki Higashino $^{2}$. \\ Masatoshi Nishimoto ${ }^{3} \cdot$ Masahiro Eriguchi $^{3} \cdot$ Kenichi Samejima $^{3} \cdot$ Kazuhiko Tsuruya $^{3} \cdot$ Tomoaki Imamura $^{1}$
}

Received: 1 May 2021 / Accepted: 17 November 2021 / Published online: 1 January 2022

(c) The Author(s) 2021

\begin{abstract}
Background The survival rate of chronic dialysis patients in Japan remains the highest worldwide, so there is value in presenting Japan's situation internationally. We examined whether aggregate figures on dialysis patients in the National Database of Health Insurance Claims and Special Health Checkups of Japan (NDB), which contains data on insured procedures of approximately 100 million Japanese residents, complement corresponding figures in the Japanese Society for Dialysis Therapy Renal Data Registry (JRDR).

Methods Subjects were patients with medical fee points for dialysis recorded in the NDB during 2014-2018. We analyzed annual numbers of dialysis cases, newly initiated dialysis cases- and deaths.

Results Compared with the JRDR, the NDB had about 6-7\% fewer dialysis cases but a similar number of newly initiated dialysis cases. In the NDB, the number of deaths was about $6-10 \%$ lower, and the number of hemodialysis cases was lower, while that of peritoneal dialysis cases was higher. The cumulative survival rate at dialysis initiation was approximately 6 percentage points lower in the NDB than in the JRDR, indicating that some patients die at dialysis initiation. Cumulative survival rate by age group was roughly the same between the NDB and JRDR in both sexes.

Conclusion The use of the NDB enabled us to aggregate data of dialysis patients. With the definition of dialysis patients used in this study, analyses of concomitant medications, comorbidities, surgeries, and therapies will become possible, which will be useful in many future studies.
\end{abstract}

Keywords Chronic renal insufficiency $\cdot$ Peritoneal dialysis $\cdot$ Administrative claims database $\cdot$ NDB $\cdot$ National database

\section{Introduction}

The survival rate of chronic dialysis patients remains higher in Japan than in the United States and Europe [1-3]. This reflects the high level of dialysis treatment in the country, and the benefit of its universal health coverage system. Thus, there is value in presenting Japan's situation to the world.

Tatsuya Noda

t-n@umin.ac.jp

1 Department of Public Health, Health Management and Policy, Nara Medical University, 840 Shijo-Cho, Kashihara, Nara 634-8521, Japan

2 Management Innovation Division, Mitsubishi Research Institute, Inc, 10-3, Nagatacho 2-Chome, Chiyoda-Ku, Tokyo 100-8141, Japan

3 Department of Nephrology, Nara Medical University, 840 Shijo-Cho, Kashihara, Nara 634-8521, Japan
In Japan, the Japanese Society for Dialysis Therapy (JSDT) manages the JSDT Renal Data Registry (JRDR), which is a large-scale dialysis statistics registry based on an annual nationwide survey covering various aspects, such as the numbers of patients who underwent hemodialysis (HD), hemodiafiltration, hemofiltration, hemoadsorption, and peritoneal dialysis (PD), as of December 31 each year. Also covered in the registry are the number of newly introduced dialysis cases and the number of deaths among dialysis patients. Because frontline physicians participated in this survey, the aggregate data in the JRDR are considered almost completely accurate, albeit with some selection biases $[4,5]$. Given the high response rate of the medical facility questionnaires ( $98.7 \%$ in 2018 ), the registry is considered the annual dialysis census in Japan.

However, physicians expend a great deal of time and effort to extract necessary data of individual patients to complete the JSDT questionnaire, so a simpler alternative 
is awaited. The only possible alternative is the National Database of Health Insurance Claims and Special Health Checkups of Japan (NDB) [6]. The NDB is a comprehensive database [7] containing all claims for insured treatment in Japan [8], so it is a complete enumeration of claims for medical treatment provided to individuals insured by Japan's national health insurance system [9]. It is one of the world's largest health-related databases $[10,11]$ containing complete datasets of insured treatments. By using the NDB dataset, selection bias can be reduced and thus valid aggregate figures can be obtained. Also, it is more cost effective to use than nationwide surveys.

We compared these estimates with aggregate data from the JRDR to evaluate whether the NDB can complement a part of the JRDR.

\section{Materials and methods}

\section{Ethical issues and study design}

This descriptive epidemiological study was approved by the Ethics Committee of Nara Medical University (Nos. 1123, 2831). Selected anonymized data were used, so we did not need to explain the study to patients or obtain informed consent.

\section{Data source}

Japan has a system of universal health coverage, and the NDB contains datasets of 138 million individuals (over a 5 -year period), regardless of their type of health insurance [12]. The NDB includes data on patients' personal identification information, month of issue, age group, sex, explanation of procedures implemented, diagnostic code according to the International Classification of Disease (ICD-10, medical care provided, health checkups performed, prescribed medications, and monthly amount claimed. Information about prescribed medications includes brand name, generic name, dosage, and days of medication supply. In this study, we used datasets in this nationwide database and compared them with corresponding data from the JRDR. The data from the JRDR were obtained from the JSDT website [13].

We estimated the annual number of dialysis cases, the annual number of newly initiated dialysis cases, the number of patients on dialysis for these 5 years, treatment situation by age, and the number of deaths among dialysis patients.

\section{Study population}

The JRDR contains data obtained as of the end of each year and annual figures by calendar year, and NDB data from January 2014 to December 2018 were used for aggregation. This was a retrospective cohort study.

\section{Definition of dialysis patient}

Dialysis patients were defined as patients with claims for reimbursement of any "artificial kidney" procedure. Patients who initiated dialysis were defined as those with "additional points for artificial kidney (initiation phase)" in their claims. Dialysis was classified into HD and PD. Procedure codes that define dialysis patients are shown in Online Resource 1. The number of patients who newly initiated dialysis was aggregated annually. Additional medical fee points for dialysis initiation are applicable for a month, so claims linked to 1 case of dialysis initiation can appear in 2 consecutive years. Therefore, to avoid aggregating such duplicates, we prioritized the December claim over a corresponding January claim in the following year. The subjects from the JRDR were defined as (A) all patients who were undergoing chronic dialysis treatment at medical facilities within Japan as of December 31 each year; (B) all patients who newly initiated dialysis in a given year; and (C) patients who received dialysis but withdrew in a given year for reasons, such as death and transplantation. We aggregated NDB data in a manner similar to that used for the JRDR data. We excluded patients who withdrew from dialysis due to acute kidney injury within 2 months. Thus, in the NDB, patients with fee points for dialysis for 2 consecutive months or less were excluded.

Patients who received a combination of PD and HD were counted as PD patients in the JRDR, while they were counted twice in the NDB.

\section{Definition of death}

In the NDB, there is a section to fill in outcome. Death was defined as death recorded as of the annual observation with the presence of medical fee points for dialysis in claims. Thus, withdrawal from dialysis and changes in insurance type were not considered. Patients who initiated dialysis in November 2018 or earlier were not included in this aggregation.

Cases of death in the JRDR, with "death" recorded in the outcome section of the patient report, were aggregated. When patients die after being transferred from one facility to another, the relevant information is expected to be recorded in their report kept in the initial facility as much as possible.

The survival rate was calculated and patients with medical fee points for dialysis in December 2018 were traced for up to 5 years. 
Table 1 Comparison of the total number of dialysis patients

\begin{tabular}{|c|c|c|c|c|}
\hline \multirow{3}{*}{ Year } & \multicolumn{4}{|c|}{ Number of patients ( $\%$ versus reference) } \\
\hline & \multicolumn{2}{|c|}{$\begin{array}{l}\text { Dialysis (as of the end of } \\
\text { year) }\end{array}$} & \multicolumn{2}{|c|}{$\begin{array}{l}\text { Initiation of dialysis } \\
\text { (annual) }\end{array}$} \\
\hline & NDB & JRDR & NDB & JRDR \\
\hline 2014 & $\begin{array}{l}300,069 \\
(93.6 \%)\end{array}$ & $\begin{array}{l}320,448 \\
\text { (reference) }\end{array}$ & $\begin{array}{l}37,848 \\
(98.8 \%)\end{array}$ & $\begin{array}{l}38,327 \\
\text { (reference) }\end{array}$ \\
\hline 2015 & $\begin{array}{l}305,878 \\
(94.1 \%)\end{array}$ & $\begin{array}{l}324,986 \\
\text { (reference) }\end{array}$ & $\begin{array}{l}39,136 \\
(99.2 \%)\end{array}$ & $\begin{array}{l}39,462 \\
\text { (reference) }\end{array}$ \\
\hline 2016 & $\begin{array}{l}309,700 \\
(94 \%)\end{array}$ & $\begin{array}{l}329,609 \\
\text { (reference) }\end{array}$ & $\begin{array}{l}39,408 \\
(100.2 \%)\end{array}$ & $\begin{array}{l}39,344 \\
\text { (reference) }\end{array}$ \\
\hline 2017 & $\begin{array}{l}312,955 \\
(93.6 \%)\end{array}$ & $\begin{array}{l}334,505 \\
\text { (reference) }\end{array}$ & $\begin{array}{l}40,815 \\
(99.6 \%)\end{array}$ & $\begin{array}{l}40,959 \\
\text { (reference) }\end{array}$ \\
\hline 2018 & $\begin{array}{l}313,031 \\
(92.1 \%)\end{array}$ & $\begin{array}{l}339,841 \\
\text { (reference) }\end{array}$ & $\begin{array}{l}39,370 \\
(97.3 \%)\end{array}$ & $\begin{array}{l}40,468 \\
\text { (reference) }\end{array}$ \\
\hline
\end{tabular}

$J R D R$ Japanese Society for Dialysis Therapy renal data registry, $N D B$ National database of Health Insurance Claims and Special Health Checkups of Japan

\section{Results}

\section{Total number of dialysis patients and number of patients on each type of dialysis}

The total number of dialysis patients was $6-7 \%$ lower in the NDB than in the JRDR, and the number of patients who newly initiated dialysis was almost identical (Table 1). Numbers of patients on each type of dialysis are shown alongside the total numbers of dialysis patients each year in Table 2 . The number of HD patients was lower in the NDB than in the JRDR, while the number of PD patients was higher in the NDB.

\section{Tracing of dialysis patients and verification of death cases}

Table 3 shows the length of dialysis therapy (up to 5 years) among patients who received dialysis in December 2018.
Table 2 Comparisons of the total numbers of dialysis patients, and patients on different types of dialysis

\begin{tabular}{|c|c|c|c|c|c|c|}
\hline \multirow[t]{2}{*}{ Year } & \multicolumn{2}{|c|}{ Dialysis (overall) } & \multicolumn{2}{|l|}{ HD } & \multicolumn{2}{|l|}{ PD } \\
\hline & NDB & JRDR & NDB & JRDR & NDB & JRDR \\
\hline 2014 & $\begin{array}{l}300,069 \\
(93.6 \%)\end{array}$ & $\begin{array}{l}320,448 \\
\text { (reference) }\end{array}$ & $\begin{array}{l}293,164 \\
(98.1 \%)\end{array}$ & $\begin{array}{l}298,924 \\
\text { (reference) }\end{array}$ & $\begin{array}{l}9,828 \\
(106.2 \%)\end{array}$ & $\begin{array}{l}9,255 \\
\text { (reference) }\end{array}$ \\
\hline 2015 & $\begin{array}{l}305,878 \\
(94.1 \%)\end{array}$ & $\begin{array}{l}324,986 \\
\text { (reference) }\end{array}$ & $\begin{array}{l}299,039 \\
(98.9 \%)\end{array}$ & $\begin{array}{l}302,501 \\
\text { (reference) }\end{array}$ & $\begin{array}{l}9,856 \\
(105.7 \%)\end{array}$ & $\begin{array}{l}9,322 \\
\text { (reference) }\end{array}$ \\
\hline 2016 & $\begin{array}{l}309,700 \\
(94 \%)\end{array}$ & $\begin{array}{l}329,609 \\
\text { (reference) }\end{array}$ & $\begin{array}{l}302,960 \\
(98.2 \%)\end{array}$ & $\begin{array}{l}308,503 \\
\text { (reference) }\end{array}$ & $\begin{array}{l}9,706 \\
(107.6 \%)\end{array}$ & $\begin{array}{l}9,021 \\
\text { (reference) }\end{array}$ \\
\hline 2017 & $\begin{array}{l}312,955 \\
(93.6 \%)\end{array}$ & $\begin{array}{l}334,505 \\
\text { (reference) }\end{array}$ & $\begin{array}{l}305,971 \\
(98.5 \%)\end{array}$ & $\begin{array}{l}310,708 \\
\text { (reference) }\end{array}$ & $\begin{array}{l}9,610 \\
(105.7 \%)\end{array}$ & $\begin{array}{l}9,090 \\
\text { (reference) }\end{array}$ \\
\hline 2018 & $\begin{array}{l}313,031 \\
(92.1 \%)\end{array}$ & $\begin{array}{l}339,841 \\
\text { (reference) }\end{array}$ & $\begin{array}{l}305,498 \\
(96.6 \%)\end{array}$ & $\begin{array}{l}316,113 \\
\text { (reference) }\end{array}$ & $\begin{array}{l}9,618 \\
(101.8 \%)\end{array}$ & $\begin{array}{l}9,445 \\
\text { (reference) }\end{array}$ \\
\hline
\end{tabular}

Note: In the NDB, HD patients include those who underwent HD and PD

$H D$ hemodialysis, JRDR Japanese Society for Dialysis Therapy renal data registry, $N D B$ National database of Health Insurance Claims and Special Health Checkups of Japan, $P D$ peritoneal dialysis

Table 3 Back-tracing the number and percentage of patients on continuous dialysis care in the 5 years preceding 2018 as the reference year

\begin{tabular}{|c|c|c|c|c|c|c|c|}
\hline & & End of 2018 & 1 year earlier & 2 years earlier & 3 years earlier & 4 years earlier & 5 years earlier \\
\hline \multirow[t]{4}{*}{ NDB } & \multirow[t]{2}{*}{ Men } & 206,089 & 179,230 & 155,665 & 135,016 & 116,659 & 100,093 \\
\hline & & $(100 \%)$ & $(87.0 \%)$ & $(75.5 \%)$ & $(65.5 \%)$ & $(56.6 \%)$ & $(48.6 \%)$ \\
\hline & \multirow[t]{2}{*}{ Women } & 110,776 & 98,730 & 87,816 & 78,163 & 69,125 & 60,787 \\
\hline & & $(100 \%)$ & $(89.1 \%)$ & $(79.3 \%)$ & $(70.6 \%)$ & $(62.4 \%)$ & $(54.9 \%)$ \\
\hline \multirow[t]{4}{*}{ JRDR } & \multirow[t]{2}{*}{ Men } & 213,881 & & & & & 107,577 \\
\hline & & $(100 \%)$ & & & & & $(50.3 \%)$ \\
\hline & \multirow[t]{2}{*}{ Women } & 113,173 & & & & & 64,110 \\
\hline & & $(100 \%)$ & & & & & $(56.6 \%)$ \\
\hline
\end{tabular}

$J R D R$ Japanese Society for Dialysis Therapy renal data registry, $N D B$ National database of Health Insurance Claims and Special Health Checkups of Japan 
In the JRDR, only data from a 5-year period were aggregated, so data in the previous 1-4 years are missing in the table. When comparing NDB and JRDR, differences in the proportions of men and women who received dialysis for 5 years were $1-2 \%$, and the proportions in 2018 were the same in both databases.

Figure 1 shows 5 -year survival curves who initiated dialysis during January 2014-December 2014. The survival rate at dialysis initiation was 6 percentage points lower in the NDB than in the JRDR, indicating that the NDB includes more patients who die soon after dialysis initiation.

To examine the data in more detail, we summarized 4-year cumulative survival rates of patients who initiated dialysis in 2014 by age group in Table 4 . To comply with the data disclosure rules of the NDB, exact patient numbers are not shown in some parts of the table, and 4-year cumulative survival rates of patients aged 2-14 years and 15-29 years are not reported here. Cumulative survival rates were roughly the same between the NDB and JRDR, though some patient numbers differed.

The annual number of deaths among dialysis patients is shown in Table 5. The ratio of the number of deaths in the JRDR to that in the NDB was around 93\% each year. Thus, the number of deaths tended to be $7 \%$ lower in the NDB than in the JRDR, similar to the number of patients.

\section{Discussion}

\section{Definition of dialysis patients and comparison of the number of patients}

The number of dialysis patients was 7\% lower in the NDB than in the JRDR. The NDB includes data about insured treatment only and does not include information about patients who completely rely on public assistance, meaning that the number of dialysis patients is likely to be underestimated. According to a government survey, public assistance recipients totaled 2.09 million in February 2019 [14], accounting for $1.6 \%$ of the population. Meanwhile, among patients who applied for medical expense grants for intractable disease treatment, public assistance recipients totaled $2.3 \%(20,930 / 892,123)$ [15]; the actual figure could be higher because some patients with an intractable disease did not apply for the grant if they were already living on social welfare benefits [16]. The proportion is likely to be higher than $2.3 \%$ if patients are receiving continuous treatment, and there is uncertainty about whether this figure can be applied to dialysis patients. However, this problem will be solved in the future because data related to public assistance recipients will become available from the NDB for aggregation after amendment of the system.

Also, the NDB does not contain data of a very small population of untraceable patients, likely because claims were not processed electronically due to high medical expenses (transplantation, etc.). The effect on the population

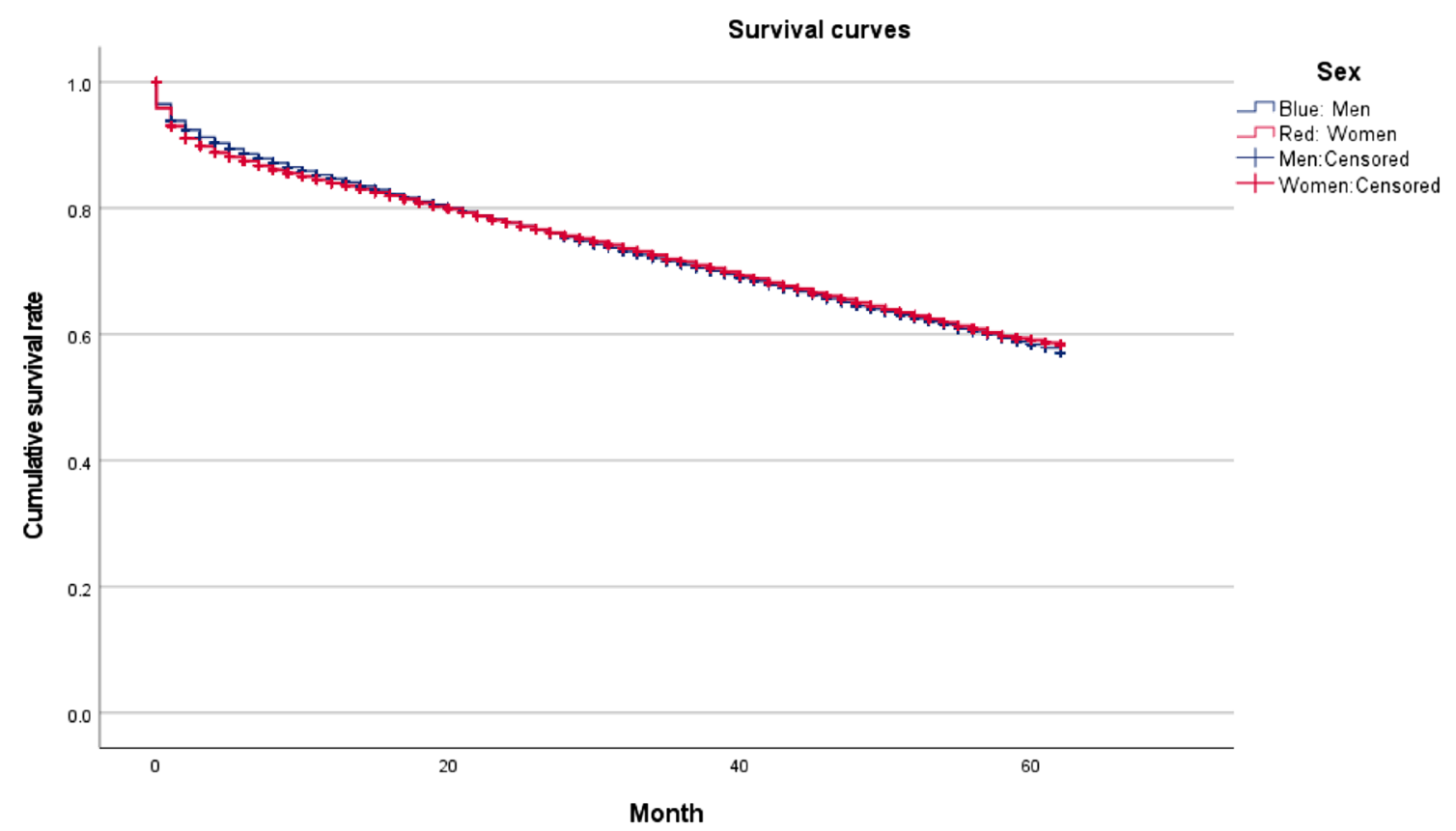

Fig. 1 Five-year survival curves of patients who initiated dialysis between January 2014 and December 2014 
Table 4 Four-year survival rate of patients who initiated dialysis in 2014 by age group

\begin{tabular}{|c|c|c|c|c|c|c|c|}
\hline & & \multicolumn{3}{|l|}{ NDB } & \multicolumn{3}{|l|}{ JRDR } \\
\hline & & Men & Women & Total & Men & Women & Total \\
\hline \multirow[t]{2}{*}{ Age $0-14$} & No. of patients & $<10$ & $<20$ & 21 & 10 & 15 & 25 \\
\hline & Four-year cumulative survival rate & - & - & - & 0.68 & 0.91 & 0.83 \\
\hline \multirow[t]{2}{*}{ Age 15-29 } & No. of patients & $70-79$ & $40-49$ & 115 & 131 & 76 & 207 \\
\hline & Four-year cumulative survival rate & - & - & - & 0.97 & 0.91 & 0.95 \\
\hline \multirow[t]{2}{*}{ Age $30-44$} & No. of patients & 571 & 199 & 770 & 1,281 & 478 & 1,759 \\
\hline & Four-year cumulative survival rate & 0.95 & 0.95 & 0.95 & 0.94 & 0.95 & 0.94 \\
\hline \multirow[t]{2}{*}{ Age 45-59 } & No. of patients & 2,774 & 1,044 & 3,818 & 4,021 & 1,500 & 5,521 \\
\hline & Four-year cumulative survival rate & 0.90 & 0.91 & 0.90 & 0.89 & 0.91 & 0.90 \\
\hline \multirow[t]{2}{*}{ Age $60-74$} & No. of patients & 7,814 & 3,229 & 11,043 & 9,762 & 4,076 & 13,838 \\
\hline & Four-year cumulative survival rate & 0.76 & 0.81 & 0.78 & 0.77 & 0.82 & 0.78 \\
\hline \multirow[t]{2}{*}{ Age 75-89 } & No. of patients & 10,360 & 5,516 & 15,876 & 8,321 & 4,995 & 13,316 \\
\hline & Four-year cumulative survival rate & 0.57 & 0.61 & 0.59 & 0.56 & 0.59 & 0.57 \\
\hline \multirow[t]{2}{*}{ Age $90+$} & No. of patients & 950 & 931 & 1,881 & 347 & 352 & 699 \\
\hline & Four-year cumulative survival rate & 0.49 & 0.52 & 0.50 & 0.34 & 0.40 & 0.37 \\
\hline \multirow[t]{2}{*}{ Not recorded } & No. of patients & & & & 1 & 2 & 3 \\
\hline & Four-year cumulative survival rate & & & & 0.00 & 0.00 & 0.00 \\
\hline \multirow[t]{2}{*}{ Total } & No. of patients & 22,549 & 10,975 & 33,524 & 23,874 & 11,494 & 35,368 \\
\hline & Four-year cumulative survival rate & 0.69 & 0.70 & 0.69 & 0.72 & 0.72 & 0.72 \\
\hline
\end{tabular}

$J R D R$ Japanese Society for Dialysis Therapy renal data registry, $N D B$ National database of Health Insurance Claims and Special Health Checkups of Japan
Table 5 Annual number of deaths among dialysis patients

\begin{tabular}{llllll}
\hline & 2014 & 2015 & 2016 & 2017 & 2018 \\
\hline NDB & 28,218 & 29,129 & 30,236 & 31,024 & 31,300 \\
& $(91.9 \%)$ & $(93.8 \%)$ & $(95.1 \%)$ & $(95.4 \%)$ & $(92.4 \%)$ \\
JRDR & 30,707 & 31,068 & 31,790 & 32,532 & 33,863 \\
& (reference) & (reference) & (reference) & (reference) & (reference)
\end{tabular}

$J R D R$ Japanese Society for Dialysis Therapy renal data registry, $N D B$ National database of Health Insurance Claims and Special Health Checkups of Japan

of dialysis patients is unknown but the inclusion of such untraceable cases needs to be taken into consideration.

Meanwhile, most of the data were entered manually in the JRDR, which can be either overestimation or underestimation. As example of overestimation, some patients who were hospitalized at the time of the statistical survey might have been doubly counted at the outpatient facility they had visited previously. Also, because many patients are over 100 years old, patients who have died may be treated as alive. Factors contributing to the underestimation include the possibility that a small number of facilities not belonging to JSDT are not included, and that data are not entered due to ambiguity in the primary entry facility.

Aggregate numbers of patients who initiated dialysis were almost the same in the NDB and the JRDR, although that in the NDB was slightly lower than that in the JRDR.
This similarity might be due to some patients being insured at initiation of dialysis but then becoming exempt as their situation changed, for example, patients who begin to receive public assistance due to their inability to work.

The number of HD patients was lower in the NDB than in the JRDR, while that of PD patients was higher in the NDB. Patients who received a combination of PD and HD were counted twice in the NDB, whereas they were counted as PD patients in the JRDR. It should be noted that the number of patients might be lower than the actual number because claims for fee points for either HD or PD are accepted within a month. Some patients receive home PD, which might have contributed to the high number of PD patients in the NDB. Home PD patients usually make monthly visits to clinics and/or hospitals, but some opt for home-based medicine because outpatient visits are difficult. Dialysis treatments in such cases might not be reflected in the JRDR as they were not performed at medical facilities. However, this is a limited case. Also, completely switching from PD to HD can be handled as the combination of PD and HD depending on the timing of data aggregation, and this might also have contributed to the high number of PD cases. Further, some dialysis treatments (especially PD treatments) might have been performed at medical facilities that did not participate in the JRDR but were included in the NDB. There was a report on a technique that uses several algorithms to identify patients receiving PD by using health insurance claims 
data in the United States, but it did not compare findings with data from other sources [17].

\section{Tracing the history of dialysis and deaths}

The situation of dialysis over a 5-year period prior to the reference observation point was similar in the NDB and JRDR, regardless of sex. Data in the NDB can be traced back to only around 10 years, even when including data not considered in this study, whereas data in the JRDR can be traced back 40 years. If data continue to accumulate in the NDB, then a range of data aggregation will become available.

Survival curves of patients who received dialysis between January 2014 and December 2018 showed a 5 -year survival rate of roughly $60 \%$, which is in good agreement with the results in the JRDR (i.e., $66.1 \%$ in 2018).

Including patients who received dialysis for 2 months or less in the survival curves revealed that slightly less than $10 \%$ of patients died soon after dialysis initiation. This finding is probably because the condition of patients is most severe and unexpected complications are most likely to occur around the dialysis initiation. Patients often present with unstable blood pressure due to sepsis or myocardial infarction soon after initiation of dialysis. Such a poor condition can lead to impaired renal function, requiring temporary initiation of dialysis. For example, dialysis initiation for rapid progressive glomerulonephritis due to microscopic polyangiitis often results in death due to infection. Dialysis treatment for acute renal failure was excluded if it was continued for 2 months or less in the JRDR, so there might be agreement in survival rate between the NDB and in the JRDR if the same conditions are used.

Cumulative survival rates by age group in each sex in the NDB showed similar trends to those in the JRDR, although precise comparison is difficult. One of the reasons is a difference in aggregation timing: age was determined as of the end of year in the NDB, so there can be a maximum difference of 3 months between the NDB and the JRDR. The patient questionnaire for collection of JRDR data had a response rate of $94.7 \%$, which may have affected the figures. Also, cases of withdrawal of dialysis for reasons, such as kidney transplantation, are not taken into account in the NDB, meaning that the cumulative survival rates obtained here might differ from the actual figures.

The annual number of deaths was $10 \%$ lower in the NDB than in the JRDR. Possible reasons for this include missing or incorrect data input in the NDB due to errors at medical facilities, changes in insurance type because patients began receiving public assistance, and temporary omissions due to participation in clinical studies.

\section{Summary of issues and future usability}

Key aggregate figures obtained in this study are summarized in Online Resource 2 to clarify issues to be addressed. Collectively, the aggregate figures related to dialysis obtained from the NDB closely corresponded to figures from the JRDR, even though the data sources are different. Generally, in descriptive statistics, when there are no substantial discrepancies in aggregate figures between two very different aggregation methods, it can be inferred that neither aggregate figure is the true figure, but the true figure is likely to be close to the figures estimated by those methods. Because the data aggregation methods were very different between the NDB and the JRDR, this inference is applicable.

There are biases in both databases. There is underestimation in the NDB due to the non-inclusion of data of public assistance recipients and the use of a different counting method, overestimation in the JRDR due to duplication of patients upon transfer between medical institutions, and underestimation in the JRDR due to the non-inclusion of patients who received treatments at medical facilities that do not belong to JSDT. The JRDR is built upon the enormous efforts of frontline medical professionals, which imposes a considerable burden. Automated data sampling is used in some facilities, but its wider spread is awaited. Replacing some items in the JRDR with the relevant items in the NDB would enable data to be obtained more quickly and easily.

As previously reported, research papers using health insurance claims data should provide validation for the validity of diagnosis codes [18], and thus, the definition of patients is highly important $[19,20]$. However, detailed aggregation of data related to dialysis patients is not possible with the NDB, so these databases must be selected depending on the purpose of use.

This study showed that the aggregation of dialysis patient data in the NDB is valid because it closely corresponds to aggregation of the corresponding data in the JRDR. This indicates the possibility of performing more detailed analyses (e.g., follow-up studies using concomitant medications and incidence of comorbidities as outcomes, and studies using dialysis as an exposure). Tracing the medical history before dialysis initiation is difficult using the JRDR. The present preliminary study will likely serve as a basis for many studies that use the definitions in this study.

The reasons why prognosis in dialysis patients is more favorable in Japan than overseas remain unclear [21]. Possible reasons include a lower rate of catheter use (a higher rate of arteriovenous fistula use) for vascular access [22] and longer dialysis sessions [23] in Japan. Duration of dialysis sessions in Japan is longer than that in the US, but similar to that in Europe, and shorter than that in Australia. It is noteworthy, however, that the survival rate increases as the duration of dialysis sessions increases in Japan [24]. Information, 
such as concomitant medications, incidence of comorbidities, and clinical course, will be useful in other countries.

\section{Limitations and recommendation}

Data were aggregated for each month, so a switch from HD to PD and differences due to the combination therapy were not taken into account. Test results are not available in the $\mathrm{NDB}$, so it is not possible to use the definition of patients used in the diagnostic guidelines for dialysis initiation [25].

\section{Conclusion}

Using the NDB can simplify data aggregation compared with using the JRDR, so the NDB can be considered a source of new indices. The NDB is the largest medicalrelated cohort worldwide and contains many indexes, and aggregation of its data will provide valuable knowledge on many other diseases. This will increase the utility value of the NDB, and the definitions used for dialysis patients in this study will be important for future studies.

Supplementary Information The online version contains supplementary material available at https://doi.org/10.1007/s10157-021-02163-z.

Acknowledgements The data reported herein were provided by the Japanese Society for Dialysis Therapy (JSDT). The interpretation and reporting of these data are the responsibility of the authors and in no way should be seen as an official policy or interpretation of the JSDT. This work was supported by JSPS KAKENHI Grant Numbers 18H04126, 19K19464, and 20H00623, and Health Science and Labor Research Grant Number H30-Medical-General-013.

Author contributions Shinichiro Kubo, and Tatsuya Noda co-wrote the first draft of the paper; all other authors contributed to substantial amendments and critical review. Shinichiro Kubo performed the statistical analysis and produced the tables and figures. Tatsuya Noda, Tomoya Myojin, Yuichi Nishioka, Saho Kanno, Masatoshi Nishimoto, Masahiro Eriguchi, Kenichi Samejima, and Kazuhiko Tsuruya provided clinical input and performed the NDB analysis and systematic reviews. Tsuneyuki Higashino led the database analysis and systematic reviews. Tomoaki Imamura was the principal investigator and directed all aspects of the project. Tatsuya Noda had full access to the study data and had final responsibility for the decision to submit the manuscript for publication. All the authors are in agreement with the content of the manuscript.

\section{Declarations}

Conflict of interest The authors have declared that no conflict of interest exists.

Ethical approval This study was approved by the Ethics Committee of Nara Medical University $(1123,2831)$. This article does not contain any studies with human participants or animals performed by any of the authors.
Open Access This article is licensed under a Creative Commons Attribution 4.0 International License, which permits use, sharing, adaptation, distribution and reproduction in any medium or format, as long as you give appropriate credit to the original author(s) and the source, provide a link to the Creative Commons licence, and indicate if changes were made. The images or other third party material in this article are included in the article's Creative Commons licence, unless indicated otherwise in a credit line to the material. If material is not included in the article's Creative Commons licence and your intended use is not permitted by statutory regulation or exceeds the permitted use, you will need to obtain permission directly from the copyright holder. To view a copy of this licence, visit http://creativecommons.org/licenses/by/4.0/.

\section{References}

1. The Japanese Society for Dialysis Therapy. "2019 Japanese Society for Dialysis Therapy Renal Data Registry" implementation plan. 2019. https://www.jsdt.or.jp/info/2644.html. Accessed: 31 Mar 2021. (Report in Japanese).

2. United States Renal Data System. 2019 USRDS Annual Data Report: Epidemiology of kidney disease in the United States. 2019. https://www.usrds.org/annual-data-report/. Accessed: 5 Sep 2021.

3. Kramer A, Boenink R, Stel VS, et al. The ERA-EDTA registry annual report 2018: a summary. Clin Kidney J. 2021;14(1):107-23.

4. The Japanese Society for Dialysis Therapy. The current situation of dialysis therapy for chronic patients in Japan. J Jpn Soc Dial Ther. 2020;53:579-632.

5. Nitta K, Goto S, Masakane I, et al. Annual dialysis data report for 2018, JSDT Renal Data Registry: survey methods, facility data, incidence, prevalence, and mortality. Ren Replace Ther. 2020;6:41

6. Ministry of Health, Labour and Welfare, Japan. Disclosure of medical claim information and specific medical examination for third party: manual for applicants for data disclosure. 2016. https://www.mhlw.go.jp/file/06-Seisakujouhou-12400000Hokenkyoku/0000117728.pdf. Accessed: 13102021 (Report in Japanese).

7. Hayashi S, Noda T, Kubo S, Myojin T, Nishioka Y, Higashino $\mathrm{T}$, Imamura $\mathrm{T}$. Variation in fracture risk by season and weather: a comprehensive analysis across age and fracture site using a National Database of Health Insurance Claims in Japan. Bone. 2019;120:512-8.

8. Health Insurance Claims Review and Reimbursement Services. Status report of health insurance claim method. 2019. https:// www.ssk.or.jp/tokeijoho/tokeijoho_rezept/tokeijoho_rezept_ h30.files/seikyu_3103.pdf. Accessed: 31 Mar 2021. (Report in Japanese).

9. Matsuda S, Fujimori K. The claim database in Japan. Asian Pac Dis Manag. 2012;6:55-9.

10. Yoshimura K. Current status of ICT policy at the Ministry of Health, Labor and Welfare. J Natl Inst Public Health. 2018;67:158-65.

11. Kubo S, Noda T, Myojin T, Nishioka Y, Higashino T, Matsui H, Genta K, Imamura T. National Database of Health Insurance Claims and Specific Health Checkups of Japan (NDB): outline and patient-matching technique. bioRxiv. 2018. https://www.biorx iv.org/content/early/2018/04/02/280008.full.pdf. Accessed 3 Sep 2018.

12. Okumura Y, Sakata N, Shimizu S, Matsui H. Advancing academic research on national databases: pitfalls in claims data, Monthly IHEP. 2017; 267:16-25. (Article in Japanese). 
13. Japanese Society for Dialysis Therapy. Statistics regarding chronic dialysis patients at the end of 2018. 2019. https://docs.jsdt.or.jp/ overview/index2019.html. Accessed: 5 Sep 2021. (Report in Japanese).

14. Ministry of Health, Labour and Welfare. Public assistant recipient survey. 2019. https://www.mhlw.go.jp/toukei/saikin/hw/hihog osya/m2019/dl/02-03.xls. Accessed: 31 Mar 2021. (Report in Japanese).

15. Ministry of Health, Labour and Welfare. Report on public health administration and services. https://www.e-stat.go.jp/stat-search/ file-download? statInfId=000031873770\&fileKind=1. 2018. Accessed: 31 Mar 2021. (Report in Japanese).

16. Tao S, Zeng X, Liu J, et al. Socioeconomic status and mortality among dialysis patients: a systematic review and meta-analysis. Int Urol Nephrol. 2019;51:509-18.

17. Berger A, Edelsberg J, Inglese G, Bhattacharyya S, Oster G. Identification of patients receiving peritoneal dialysis using health insurance claims data. Clin Ther. 2009;31:1321-34.

18. van Oosten MJM, Logtenberg SJJ, Edens MA, Hemmelder MH, Jager KJ, Bilo HJG, Stel VS. Health claims databases used for kidney research around the world. Clin Kidney J. 2021;14:84-97.

19. Winkelmayer WC, Schneeweiss S, Mogun H, Patrick AR, Avorn J, Solomon DH. Identification of individuals with CKD from Medicare claims data: a validation study. Am J Kidney Dis. 2005;46:225-32.

20. van Walraven C, Bennett C, Forster AJ. Administrative database research infrequently used validated diagnostic or procedural codes. J Clin Epidemiol. 2011;64:1054-9.
21. Kimata N, Tsuchiya K, Akiba T, Nitta K. Differences in the characteristics of dialysis patients in Japan compared with those in other countries. Blood Purif. 2015;40:275-9.

22. Robinson BM, Akizawa T, Jager KJ, Kerr PG, Saran R, Pisoni RL. Factors affecting outcomes in patients reaching end-stage kidney disease worldwide: differences in access to renal replacement therapy, modality use, and haemodialysis practices. Lancet. 2016;388:294-306.

23. Robinson BM, Bieber B, Pisoni RL, Port FK. Dialysis Outcomes and Practice Patterns Study (DOPPS): its strengths, limitations, and role in informing practices and policies. Clin J Am Soc Nephrol. 2012;7:1897-905.

24. Tentori F, Zhang J, Li Y, Karaboyas A, Kerr P, Saran R, Bommer J, Port F, Akiba T, Pisoni R, Robinson B. Longer dialysis session length is associated with better intermediate outcomes and survival among patients on in-center three times per week hemodialysis: results from the Dialysis Outcomes and Practice Patterns Study (DOPPS). Nephrol Dial Transplant. 2012;27:4180-8.

25. Watanabe Y, Yamagata K, Nishi S, et al. Japanese society for dialysis therapy clinical guideline for "hemodialysis initiation for maintenance hemodialysis." Ther Apher Dial. 2015;19(Suppl 1):93-107.

Publisher's Note Springer Nature remains neutral with regard to jurisdictional claims in published maps and institutional affiliations. 